\title{
UNA APROXIMACIÓN AXIOLÓGICA A LA RESTAURACIÓN DEL ARTE CONTEMPORÁNEO. DE MATERIA Y DE VALORES ESENCIALES EN LA OBRA
}

Data recepción: 2013/10/14

Data aceptación: 2014/06/13

Rosario Llamas Pacheco

Contacto autora: rllamas@crbc.upv.es

\author{
Universitat Politècnica de Valencia
}

\section{RESUMEN}

Las obras de arte contemporáneas son seres vivos, no sólo en sentido figurado, también en ocasiones, en un sentido literal. La conservación y restauración de nuestro patrimonio más reciente ha debido ir adaptando su código deontológico a las nuevas situaciones y categorías de problemas que hoy en día se presentan. El artículo pretende realizar un recorrido por las líneas esenciales que definen estas tipologías de obras, en relación con los criterios a seguir para su conservación y en relación con los problemas técnicos y conceptuales más habituales que afectan a su restauración. Así, se analiza el cambio de paradigma producido ante la necesidad de la actualización teórica para el ámbito específico de la restauración del arte contemporáneo.

Palabras clave: axioma, restauración, arte contemporáneo, criterios, valores

\section{ABSTRACT}

Contemporary works of art are living beings, both in a figurative and, on occasion, a literal sense. The code of ethics that applies to the conservation and restoration of our most recent heritage has had to be adapted to the situations and problems that arise today. This article an overview of the essential characteristics of the these types of works, in relation both to the criteria observed in and to the most common technical and conceptual problems impacting on their restoration. In doing so, it analyses the paradigm shift caused by the need to update theory pertaining to the specialist field of contemporary art restoration.

Keywords: axiom, restoration, contemporary art, criteria, values

\section{De lo material en el arte contempo-} ráneo

Hoy en día es evidente la diversidad de materiales utilizados en la concreción del objeto artístico. Es posible encontrar, dentro del vasto campo del arte actual, obras en las que realmente el artista ha utilizado, por ejemplo, seres vivos como partes esenciales y simbólicas de las mismas, dejando patente que la complejidad de los elementos constitutivos de las nuevas propuestas plásticas, propuestas que por otra parte, ya no pueden ser incluidas dentro de las categorías tradicionales de las Bellas Artes.

En cuanto a nuestro objeto artístico actual, que debe ser conservado como parte del patri- monio cultural a legar a las futuras generaciones, cabe una aproximación definitoria.

Si lo que deseamos es caracterizar el tipo de obra sobre la que deberá actuar un conservador de arte contemporáneo, podríamos abordar la cuestión alejándonos de la clasificación artística basada en la periodización histórica, y centrándonos en el estudio de los aspectos materiales de las obras producidas a partir de la segunda mitad del siglo XX (aunque desde a principios del siglo $X X$ algunas obras fueron ejecutadas de manera poco convencional). En este sentido, son conocidas las diferencias técnicas y materiales entre la producción artística reciente y la tradicional, así como el distanciamiento de las clásicas disciplinas incluidas en las Bellas Artes. 
En este sentido defendemos el término "no convencional", que desde aquí proponemos para referirnos a un tipo de propuesta plástica que presenta las siguientes características definitorias: la creciente complejidad técnica; la combinación de diversos materiales en un mismo objeto artístico; la introducción de nuevos valores semánticos en los propios materiales; la elaboración de un discurso artístico complejo que podría llegar en ocasiones incluso a la desmaterialización de la obra de arte; el uso de nuevos elementos plásticos como el movimiento, la luz, la vida, el sonido, el cuerpo humano, el paso del tiempo...

Así, el arte "no convencional" sería entendido como el producido con importantes diferencias técnicas, materiales y conceptuales con respecto al arte de siglos anteriores o arte academicista.

Es sabido que desde principios de siglo se introdujeron en el arte objetos de la vida cotidiana, objetos que fueron dotados de valores estéticos, culturales o sociales, gracias al trabajo intelectual de los artistas, los cuales generaron obras donde el uso de la materia nada tenía que ver con el de las obras tradicionales y donde la experimentación se puso al servicio de la creatividad. El resultado fue la aparición de obras cuya materia quedaba supeditada al trabajo intelectual del artista o a factores novedosos como el azar.

Sin embargo, en el arte contemporáneo también encontramos obras ejecutadas de manera tradicional. En estas obras la materia no es motivo de experimentación y por ello no plantea para el conservador problemas técnicos de resolución compleja.

\section{Los distintos sectores de actuación en el arte actual}

¿Cómo es posible clasificar la gran variedad de objetos artísticos que se producen en la actualidad? ¿Debe el conservador de arte contemporáneo estar preparado para cualquier problema técnico? ¿Cómo abordar la adaptación deontológica necesaria para conservar obras en las que no se produce una concreción material?

Ante la amplitud de estos problemas, es importante aplicar una correcta metodología de actuación que garantice que el proceso de toma de decisiones se lleva a cabo correctamente. Son varios los autores que han abordado el estudio de los factores discrepantes que envuelven ese proceso de toma de decisiones ${ }^{1}$. Pretendemos aportar algún avance en el campo, al ampliar la habitual lista de aspectos que intervienen y que incluye: opinión del artista, historicidad de la obra, autenticidad, originalidad, legislación, posibilidades técnicas, funcionalidad, con el factor del mercado del arte, que en ocasiones ejerce gran presión sobre los propios artistas y sobre los conservadores, decantando la balanza hacia uno u otro tratamiento de intervención.

Al hablar de los distintos sectores de actuación en el arte contemporáneo no nos referimos únicamente a los distintos tipos de obras con necesidad de restauración que podemos encontrar, sino que incluimos también una categorización de problemas específicos típicos del "arte no convencional".

Althöfer ${ }^{2}$ ya estableció una subdivisión que podría ampliarse y matizarse, pero que supone un punto de partida en el intento de categorizar, no ya la obra de arte en tanto que objeto material, sino los diversos problemas (tanto de tipo técnico como teórico) a los que el conservador de arte contemporáneo podría enfrentarse.

En relación con el arte a la manera tradicional es necesario señalar que las obras bidimensionales, de caballete, o de concepción clásica, que han sido ejecutadas con materiales de los siglos $X X$ y $X X I$, en ningún caso se comportan como las realizadas con los utilizados en las obras de siglos anteriores (Fig. 1). Por ello, aun-

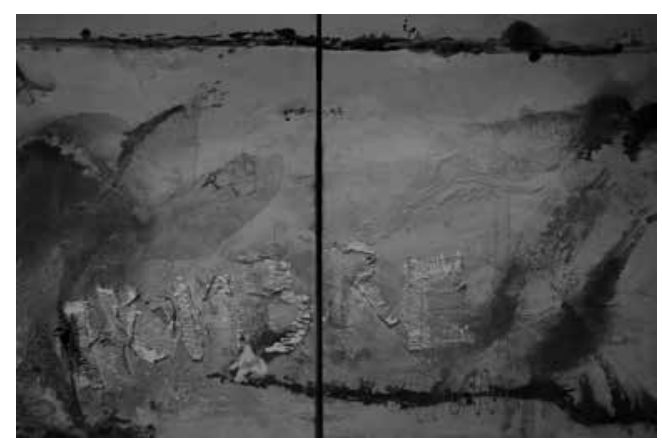

Fig. 1. Detalle de la obra Siempre buscando un motivo para el arte, de Rosario Llamas, realizada en 2011. En ella se aprecia la heterogeneidad de la superficie y la combinación de diferentes técnicas pictóricas y texturas. 
que en principio pueda parecer que su comportamiento físico será parecido al de aquellas, éste es absolutamente diferente, tanto en relación con el envejecimiento de la materia, como en relación con su respuesta ante los tratamientos de conservación más o menos habituales.

Por ello, podría aceptarse este tipo de manifestación como una categoría diferenciada con respecto al arte tradicional, pues de facto, constituyen un conjunto de obras de naturaleza específica, una naturaleza que les ha sido conferida por el uso de materiales de tipo industrial. Por su parte, el artista contemporáneo utiliza los materiales de manera específica, sin que en muchas ocasiones se hayan tenido en cuenta las reglas de ejecución académicas, podría decirse que con los mismos materiales, cada artista realizará un obra técnicamente diferente, también en la pintura de caballete.

Por estos motivos el acercamiento del restaurador a estas obras debe ser extremadamente prudente, ya que la mayoría de tratamientos empleados para la restauración de la pintura de caballete tradicional, podrían llegar a afectar gravemente a una obra contemporánea.

Otra categoría artística específica del arte contemporáneo se refiere al arte monocromo. Este tipo de arte, como el que utiliza la tinta plana, introduce al conservador en problemas de tipo filosófico, pues el paso del tiempo llevará implícita, inexorablemente, la transformación de los matices de color, y por lo tanto, el alejamiento de la apariencia prístina.

Por su parte, las superficies pictóricas pueden atesorar gran cantidad de los valores estéticos de la obra. Los acabados aterciopelados y el aspecto mate y sin interrupción formal ni de matiz, buscados y deseados por el artista, pueden verse gravemente afectados por pequeñas patologías que en otras obras no supondrían un problema considerable. Si el paso del tiempo altera la condición de la materia puede afectar a la significación de la misma, generando en este caso un conflicto de muy difícil resolución para el conservador. Podríamos introducir en este punto un nuevo concepto: el de ruina de la obra contemporánea.

Podemos encontrar, por otro lado, obras realizadas con materiales inestables o por combina- ción inestable de materiales. Estas obras llevan implícitas una degradación rápida debida al carácter de la materia utilizada, pero también debida en ocasiones a una incorrecta manipulación o combinación de la misma. En estos casos, aun no siendo intención del artista dotar a su creación de un carácter efímero, el comportamiento inestable de los materiales generará un conflicto entre la intención del artista y el comportamiento real de la obra, sometida a los agentes de deterioro (Fig. 2). En resumen, el conflicto se presentará cuando exista la intención de conservación de un objeto que por su naturaleza se degrada rápidamente, pues los procesos de degradación se producirán independientemente de la intención artística. La técnica de ejecución de la obra conllevará una degradación demasiado rápida en contra de la voluntad del artista.

El caso del arte efímero es una categoría artística temporal diferente, entendida y asumida de este modo. El artista concibe su obra con la intención de desaparición y esta naturaleza está presente desde el momento de la creación. No podríamos hablar de arte efímero en el caso anterior, pues en aquél, la desaparición de las obras no es debida a la intención artística sino a una mala ejecución técnica. No existirá conflicto en el caso del arte efímero, pues la suerte que sufrirá la obra es determinada por el propio autor.

En relación con el arte cinético, sería adecuado otorgar a este tipo de obras una categoría propia dentro del arte contemporáneo ya que en este caso, es común la necesidad de anteponer al resto de valores, como valor esencial, la nece-

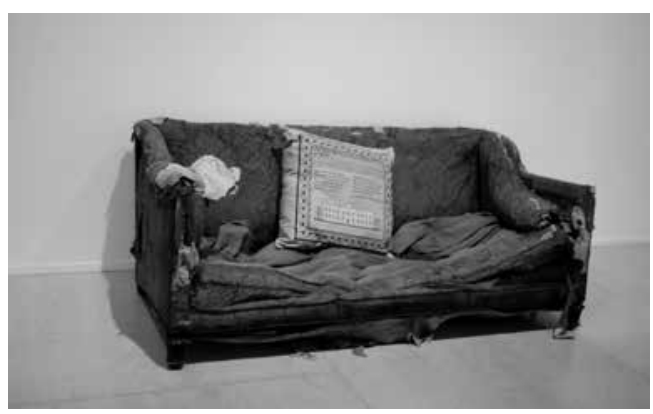

Fig. 2. Trickle up, 1992, Sofá desvencijado y cojín bordado. Expuesto por primera vez en The Vision Thing, John Weber Gallery. Expuesto en el Museo Nacional Reina Sofía del 14 al 23 de Julio de 2012. El objeto simbólico dotado de valores sociales, culturales y políticos. 
sidad imperiosa de conservación de la funcionalidad. Los distintos valores que atesora el objeto simbólico: valores estéticos, históricos, icónicos, sociales, culturales, deberán supeditarse al valor de funcionalidad en el caso de obras en las que la esencialidad artística está depositada en el movimiento del objeto.

Otro sector específico del arte contemporáneo son las instalaciones. La importancia de la idea de la obra deviene en este caso fundamental. Estas obras, en las que la interacción con el público habitualmente es necesaria, presenta grandes diferencias con respecto al arte tradicional, pues el espacio, el movimiento y otros elementos se introducen como agentes constructores de las mismas. El espectador será llamado a aprehender la obra, a experimentarla en función de su propio bagaje personal y las herramientas conceptuales adquiridas previamente.

En relación con la materia instalada, cualquier tipo de elemento, también con vida real, como por ejemplo animales o plantas, así como objetos cotidianos u objetos tecnológicos, entre otros, podrían ser dotados de valores artísticos. Por otra parte, en ocasiones es necesaria la reedición, re-materialización, o nueva concreción de la idea para adaptar la apariencia de las obras a los diferentes espacios expositivos. La necesidad real de gestionar estos cambios ha tenido como consecuencia una actualización de la teoría de la conservación con el fin de asumir las diversas mutaciones a las que los artistas y los restauradores, una vez valorados los distintos factores discrepantes que determinan las intervenciones, someten a las obras. La variedad de los problemas, su complejidad, y los nuevos agentes involucrados en la conservación del arte, han hecho necesaria una adaptación o revisión de los paradigmas tradicionales que han guiado hasta hoy la conservación de los bienes culturales (Fig. 3). Así, dado que la sustitución de la materia autorizada por el artista y admitida conceptualmente, es en ocasiones necesaria, la figura del conservador evoluciona y se adapta al concepto de obra viva, en tanto que ésta nace, se transforma y puede entrar en un periodo de decadencia y muerte. El conservador pues, adapta sus funciones y se convierte en gestor del cambio, al encontrarse el arte contemporáneo en una inestabilidad permanente.

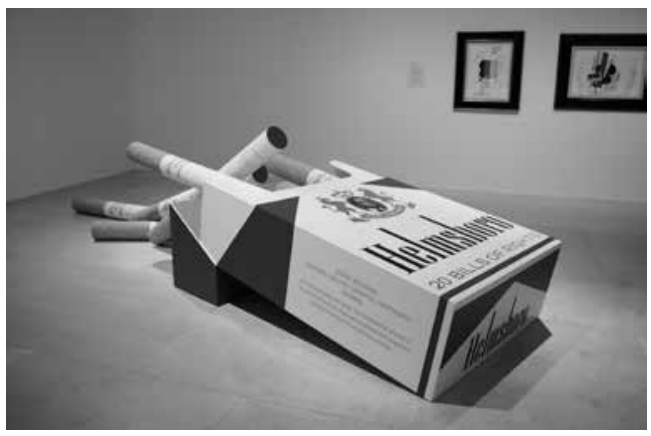

Fig. 3. Helmsboro Country, 1990, obra de Hans Haacke. Serigrafías y fotografías sobre Madera, cartón y papel. Colección del artista. Expuesto por primera vez: Helmsboro Conuntry, John Weber Gallery, Nueva York.

En el caso de las instalaciones, esta necesidad de gestión de la transformación es, si cabe, más acuciante, pues la obra concebida para un espacio concreto, para un momento específico, podría sufrir transformaciones al ser materializada de nuevo en el futuro (Fig. 4). Y ante la

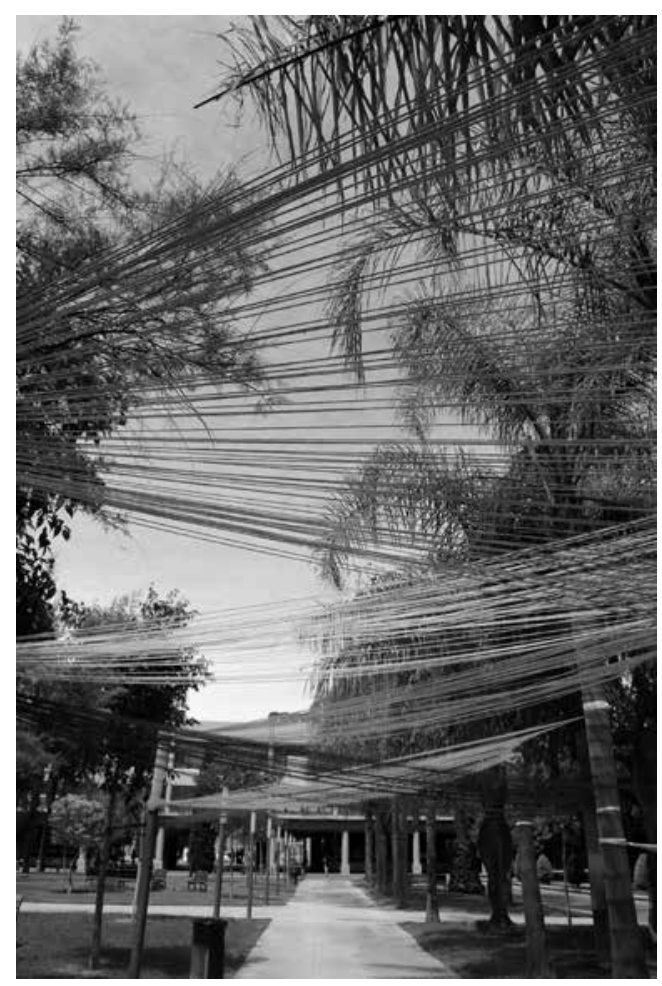

Fig. 4. Instalación en el campus de la Universidad Politécnica de Valencia en mayo de 2013. La obra ha sido generada a partir de materiales reciclados. 
dificultad de establecer límites o fronteras en la definición de las nuevas propuestas plásticas, que pueden utilizar todos los recursos disponibles a su alcance, podríamos apuntar que la concreción de la idea en este caso, podría entenderse como efímera al limitarse la importancia de los elementos materiales que la componen, de modo que el conjunto simbólico devendría lo realmente esencial (Fig. 5).

Otra cuestión es la obsolescencia tecnológica, la cual supone un gran problema para la conservación del arte reciente. Son numerosas las obras que incluyen elementos tecnológicos que pueden dejar de funcionar por imposibilidad técnica. Esta categoría de problema afecta de manera transversal a varios sectores de actuación y requiere en muchas ocasiones del estudio exhaustivo de las obras en busca de sus aspectos esenciales, así como la documentación de aquellos elementos que eventualmente pudieran ser sacrificados.

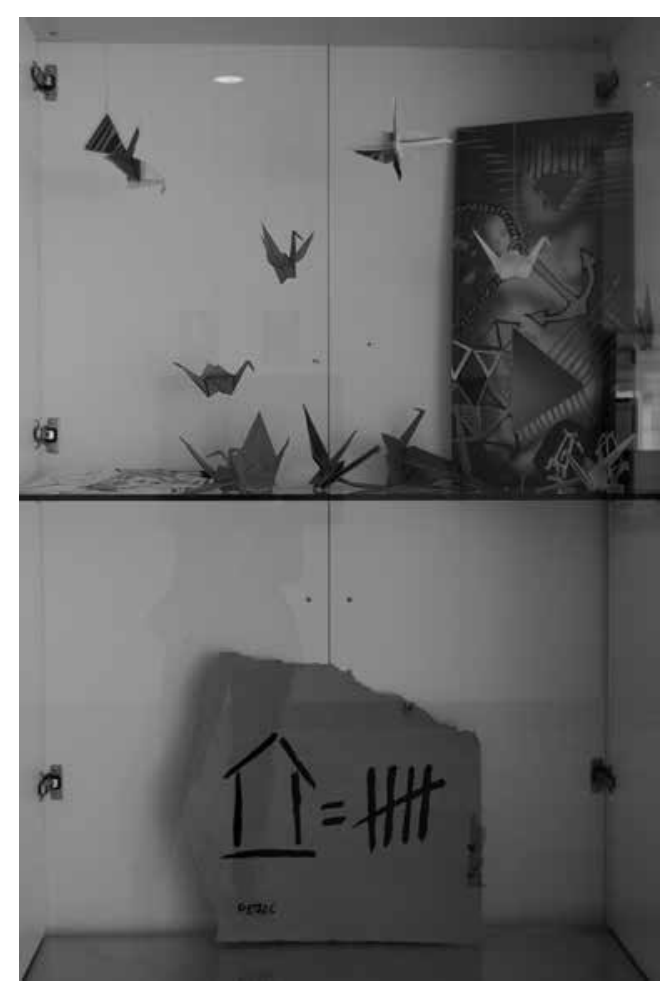

Fig. 5. Instalación en la Facultad de Bellas Artes de Valencia, en mayo de 2013. Variedad de materiales dotados de significación son utilizados por los artistas.
Pero hay más sectores de actuación dentro de la producción artística actual. El videoarte se ha convertido en un medio de expresión cada día más utilizado por los artistas y por lo tanto, más presente en los museos. Su conservación lleva implícito el estudio de las dos polaridades de que constan las obras: de un lado, el soporte de la imagen tecnológica, y de otro, el medio reproductor necesario para su visualización. En este sentido, el problema de la obsolescencia tecnológica afecta seriamente al conservador de arte contemporáneo, un problema que es fácilmente visible en el caso del videoarte, pero que también afecta a otras obras en las que determinados productos industriales han dejado de estar disponibles en el mercado.

El artista contemporáneo se encuentra hoy en día sumido en la búsqueda del arte total. Un arte que debe expresarse haciendo uso de todos los elementos de que dispone en la actualidad: sensoriales, tecnológicos, sociales... Así, son introducidos en las obras nuevos agentes artísticos, como el sonido, la luz, el movimiento o el tiempo, que marcan grandes diferencias con respecto a las obras de siglos anteriores. Aparece pues la necesidad de documentarlos, comprenderlos y en ocasiones experimentar, ante la necesidad de su conservación.

Otro problema específico del arte contemporáneo es la conservación de los objetos realizados con materiales poliméricos, es decir, la conservación de los objetos de plástico que pueden conformar las obras por sí mismos o formar parte de ellas. La conservación de estos objetos, que se degradan a menudo rápidamente, podría incluirse dentro de la categoría general que se refiere a las obras que están ejecutadas con materiales inestables o mal combinados entre sí, comentada anteriormente.

Sin embargo, la complejidad técnica que envuelve a los plásticos y a su conservación ha dado como resultado una línea de estudio específica del arte contemporáneo, que en la actualidad tiene un gran desarrollo científico. El estudio de los plásticos puede enfocarse también, dentro de la disciplina de la conservación y restauración, como el conocimiento de los materiales que se introducen en las obras de arte durante los procesos de restauración. El comportamien- 
to de las sustancias filmógenas de tipo sintético utilizadas con un fin de conservación, es conocido ampliamente; sin embargo, no lo es tanto el comportamiento que tendrán los plásticos moldeados y obtenidos industrialmente que han sido incorporados a las obras. Esta línea de estudio es necesaria y se amplía constantemente, dada la necesidad de conservar la gran cantidad de objetos de plástico presentes en las colecciones de los museos.

También el arte de acción es específico de siglo XX. La identificación de la vida con el arte acaecida en la década de los sesenta, dio como resultado importantes incorporaciones. En la performance existe un guión preestablecido: se trataría de una representación que se produce en un lugar y en un momento determinado, donde la relación con el público es importante para el artista. Para algunos artistas el evento artístico es directo e irrepetible y sólo puede darse a conocer con posterioridad gracias a la fotografía o al vídeo. Por su parte, el happening hace uso del público para introducir elementos no predecibles en el acto artístico. Quizá sea ésta una de las diferencias importantes entre uno y otro. La documentación del evento deviene fundamental en ambos casos.

Cabe señalar por último la importancia de la fotografía en tanto que sector específico de actuación, pues es un medio de expresión artística de gran importancia que forma parte en gran medida de las colecciones museísticas. Por sí misma, o combinada con otros elementos en la concreción de obras de carácter híbrido, conlleva problemas técnicos específicos de conservación que exigen al conservador una formación profunda, dada la variedad de técnicas con las que podría encontrarse.

\section{La idea, el concepto y los valores en el bien simbólico}

Varios autores han apuntado que el arte contemporáneo se degrada a sí mismo ${ }^{3}$. Es ésta una afirmación que podría analizarse más pormenorizadamente. En el caso de la materia de las obras de arte mal ejecutadas, o realizadas con materiales de baja calidad, podría tener justificación. No estaría en la intención del artista la desaparición temprana de la obra, pero el comportamiento de la materia frente a los agentes de deterioro determinaría su desaparición. El paso del tiempo alteraría en este caso la condición de la materia, de manera que ésta pudiera desaparecer, o quedar afectada e imposibilitada para transmitir su discurso estético. En ambos casos, el efecto del tiempo sobre los materiales tendría una consecuencia catastrófica, al producirse un conflicto entre la intención de duración del objeto y la imposibilidad técnica de conservarlo.

Otro es el caso de las obras en las que podría encontrarse implícito el principio de autodestrucción. Según este principio, sería el propio artista quien, desde un principio, habría establecido la desaparición de la obra en un momento determinado, o habría concretado que el proceso de destrucción de la materia constituiría la esencialidad de la misma:

..hoy en día no basta con conocer los materiales y dominar las técnicas de restauración para hacer un buen trabajo. Ahora también hay que adentrarse en el universo intelectual, en la filosofía del artista, puesto que, de lo contrario, la restauración partiría de un punto equivocado ${ }^{4}$.

Un tercer ejemplo relacionado con el principio de autodestrucción mencionado anteriormente lo encontraríamos cuando el propio artista pretende generar "ruinas". Y en relación con este término, no hay nada que desconcierte más al conservador/restaurador que tener que aceptar ese hecho. La ruina, en el ámbito del arte contemporáneo, está presente en muchas ocasiones, podemos encontrarnos ante los restos materiales de una obra que existió durante un tiempo, como pretendía el artista, pero que ya no es capaz de cumplir su función. Esto no significa que este nuevo objeto no esté dotado de valores importantes que le hagan merecedor de ser conservado, sin embargo, sería fundamental haber entendido en el proceso de conservación su nuevo status artístico.

El objeto como bien simbólico es aprehendido socialmente, y lleva implícitos los valores históricos, sociales, culturales, que le hacen digno de entrar a formar parte del patrimonio cultural. Estos...no son sólo objetivos, sino también subjetivos... Relativos y contextuales, varían según los lugares, las épocas, y los que intervienen. 
Nunca son singulares, sino siempre complejos y están relacionados los unos con los otros ${ }^{5}$."

Por otro lado, el entramado social se relaciona con unos símbolos en constante evolución, esta relación socio-simbólica dota a las obras de sentido, en una variedad infinita de combinaciones entre materia y semántica. El significado cultural se trasmite a través del complejo social que también participa de la negociación sobre qué es lo importante en la obra. ¿Qué determina que una obra sea una obra de arte?

En la actualidad, la obra es un complejo ente simbólico, configurado a partir del medio, la materia, el entorno social y la estética. Ya con las primeras vanguardias artísticas se había producido un cambio de paradigma. A partir de ese momento la obra se convirtió en subjetiva, y el artista podía experimentar libremente con los materiales (Fig. 6). Con el fin de la Segunda Guerra Mundial, el centro artístico cambió, pero también el modo de experimentar con lo material: la obra excedió sus objetos físicos y en ocasiones su duración a través del tiempo no sería esencial. Además, al estar inmersa la manifestación artística en un entorno socio-cultural, puede incluir mensajes políticos, reivindicativos y críticos.

Ante esta realidad es necesario un cambio de paradigma: necesitamos un paradigma que nos ayude a gestionar el cambio. Porque, ¿qué debe preservar el conservador? ¿La documentación de la obra? ¿La ruina? ¿El hecho técnico que supone la materialización de la idea? ¿Los testimonios?

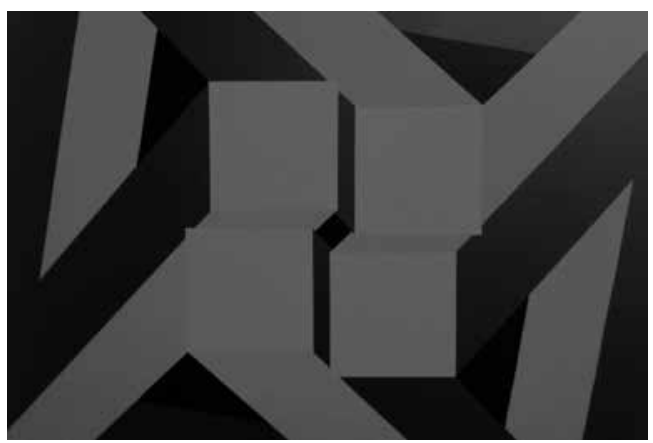

Fig. 6. Estructura, 1972, José María Yturralde López. Acrílico sobre tabla, $200 \times 200 \mathrm{~cm}$. La obra bidimiensional en el arte contemporáneo se aleja absolutamente de la tradicional, tanto en técnica como en intención artística.
Con todo, el restaurador debe enfrentarse a la conservación de la materia y debe reflexionar sobre cómo llevarla a cabo, aunque en algún caso, el paso del tiempo le colocará ante la imposibilidad de conservar lo perecedero.

En este sentido, Paolo Montorsi, desde una perspectiva más pragmática, se plantea que en algunos casos se podrá contemplar, al ser imposible su restauración, la sustitución de una parte de la obra. Se conservará el "residuo material", auténtico, pero la obra se expondrá con la pieza sustituida 6 .

Si pensamos sobre lo aconsejado por Montorsi, vemos que está demasiado influenciado por la importancia de la materia de la obra de arte, pues aún cuando sugiere la sustitución de las partes de una obra ante la incapacidad de cumplir su función, considera a las partes sustituidas "auténticas", y por consiguiente merecedoras de ser conservadas, mientras que las nuevas carecen en cierto modo de autenticidad. Y al relacionar la autenticidad de la obra con la conservación de la materia prístina, ¿cuánto se habría resentido esa "autenticidad" con la sustitución de las piezas?

Podemos también reflexionar sobre qué sentido debe dársele en arte contemporáneo a uno de los axiomas clásicos de la restauración: el del respeto por la obra de arte. Sería necesario plantear y definir bien cuáles son los objetivos del conservador, pues éste no debería plantearse congelar el objeto en un determinado estado, sino acompañar, guiar y atender a la evolución de la obra a través del tiempo, ya que nos encontramos en muchas ocasiones ante una inestabilidad permanente ${ }^{7}$.

Por ello, debería dársele un nuevo sentido a la idea del respeto por la obra de arte, ya que respetarla será entender qué rasgos son los esenciales en la misma y preservarlos, aún cuando ello vaya en detrimento de algunos elementos accesorios. En este sentido, ya se está actualizando la teoría de la restauración y la crítica de la restauración, en busca de un nuevo modelo ético más flexible, necesario ante un arte que cambia, muta y puede hasta morir.

La obra contemporánea está dotada de valores de diferente naturaleza, objetivos, pero 
también subjetivos. Estos valores implícitos en la obra en tanto que artefacto con un fin estético, provienen por un lado, del propio artista (valores estéticos, intencionales, subjetivos) y por otro, del espectador (valores estéticos y atencionales) ${ }^{8}$. Pero también provienen de otros agentes involucrados en el entendimiento de la misma. El profesional del museo dota al objeto o bien simbólico de valores estéticos de nuevo: históricos, pedagógicos, sociales, de importancia para una determinada colección. El restaurador los protegerá, incidiendo en los de cognición o expertización del objeto, por lo que,

el concepto de patrimonio ya no depende necesariamente de valores altoculturales predeterminados, sino de valores que pueden variar sustancialmente en cada caso. Ésta es una innovación fundamental, porque el patrimonio (los objetos de Restauración) deja de ser algo exterior a los grupos, algo que existe independientemente de la voluntad de los espectadores ${ }^{9} . .$.

La práctica de la restauración necesita del conocimiento de las herramientas conceptuales que parten de la filosofía y la estética para poder responder cuestiones concretas. Para ello podemos utilizar la axiología, disciplina que aparece a finales del s. XIX. El término proviene del griego "axia" y significa "que hace referencia a los valores, a la calidad". Este término es especialmente utilizado en disciplinas como la estética y a la ética.

Es interesante realizar un recorrido por los teóricos clásicos de la restauración. Aloïs Riegl publicó en 1903 la obra El culto moderno a los monumentos $^{10}$ en la cual realizó un estudio y clasificación de los valores del objeto artístico. Según este autor, los valores ligados al pasado se subdividen en valor histórico, valor de antigüedad y valor de recuerdo intencionado. En cuanto a los valores ligados al presente, Riegl distingue entre el valor de uso, el valor artístico, el valor de novedad... aunque como apunta Verbeeck ${ }^{11}$, el aporte esencial de este teórico es el hecho de poner en evidencia que estos valores pueden ser contradictorios.

Cesare Brandi realiza otra aproximación axiológica a la teoría de la conservación y restauración ${ }^{12}$. Según este autor, la obra de arte debe ser analizada atendiendo a dos valores: la instancia estética y la instancia histórica. Idealmente, estos dos valores deben ser salvaguardados, pero en el caso de discrepancia, el valor histórico quedará subordinado al estético ${ }^{13}$.

El restaurador introduce en la obra un valor subjetivo. Este valor, está vinculado a lo teleológico, a la búsqueda de un fin determinado, que se añade al estético. El restaurador debe actuar con responsabilidad y compromiso, ante la necesidad de seleccionar un proceso de intervención adecuado, ya que nuestra acción también dejará su impronta sobre la obra. Así,...el restaurador tiene que, en colaboración con los otros actores de la conservación-restauración, asumir la cuestión, la duda y la decisión final, en definitiva, asumir responsabilidades con conocimiento de causa ${ }^{14}$.

Por su parte Wetering reflexiona sobre la necesidad antropológica del ser humano de atesorar un pasado, y quizá por este motivo, de legar el suyo a las generaciones venideras ${ }^{15}$. Para Wetering, el restaurador es un promotor del arte, lo presenta según la intención del artista, aunque como apuntamos, ésta también sea mutable. Advierte Wetering del riesgo de realizar restauraciones demasiado intervencionistas, y de la posible pérdida de "autenticidad" de las obras debida a este motivo, pues como es natural, también el criterio del restaurador podría estar equivocado.

Los aspectos fundamentales en la teoría de este autor son: de un lado, como decimos, la necesidad antropológica de preservar un legado; por otro, la ética de la restauración, anclada en el papel del conservador/restaurador (que conlleva una interpretación subjetiva, y que por tanto puede ser errónea); también la participación existencial del artista; y por último, el paso inexorable del tiempo.

\section{Sobre la copia, la falsificación y el fac- símil en relación con la autenticidad del arte contemporáneo}

Hemos insistido en que la materia de la obra de arte contemporáneo se transforma, decae o muere. Ello no significa que la idea lo haga. Una obra puede consistir en un proyecto que se reeditará una y otra vez en distintas instituciones. 
La reconstrucción, o re-materialización del concepto de la obra, de la idea que el artista tuvo de la misma, implica la introducción de nuevos materiales que, según el caso, no afectará a la autenticidad del objeto simbólico.

Si esto ocurre durante los procesos de restauración, estamos obligados a analizar algunos conceptos importantes que tienen que ver con la pérdida de autenticidad de nuestras obras, como el de copia o réplica:

Una copia es la reproducción exacta de una obra artística.

Una réplica es una copia de una obra artística que reproduce con igualdad la original y que ha sido realizada por el artista o bajo su supervisión ${ }^{16}$.

Para Cesare Brandi, la diferencia entre copia, imitación y falsificación se encuentra no en el plano técnico, sino en la intención que cada uno de los objetos lleva implícita. Para Brandi, copia sería... la realización de un objeto a semejanza o como reproducción de otro objeto, a la manera o en el estilo de un determinado periodo histórico, sin otro fin que una documentación del objeto o el placer que se supone que se obtiene de él17.

Por su parte, la imitación, para este teórico, sería la obra ejecutada con la intención de llevar a engaño sobre la época, la materia o el autor.

Por último, la falsificación implicaría la introducción en el comercio o difusión de un objeto, aunque inicialmente no fuera ejecutado con tal fin, con la intención de hacerlo pasar por auténtico, produciéndose engaño sobre materia, autoría, o época.

Una copia no realizada con una intención fraudulenta, no sería pues, una falsificación.

En cuanto a la definición del término de reproducción, éste se refiere a la copia de un objeto conseguida por medios mecánicos. El término reproducción llevaría implícitas connotaciones de actualidad y métodos mecánicos de elaboración. Macarrón y González aclaran que

...hay que diferenciar entre la copia y la reproducción. En la primera se pretende una imitación del estilo o de un objeto... para lo cual no se utilizarían necesariamente medios mecánicos, sino también manuales... Con la reproducción se pueden obtener varias copias idénticas al original por procedimientos mecánicos, calcográficos, electrolíticos... ${ }^{18}$

Por su parte, el término facsímil proviene el latín "fac simile" o "haz parecido". El facsímil suele asociarse a técnicas fotográficas o serigráficas de reproducción, y pretende imitar a la perfección el objeto (escritos, dibujos, libros...).

Podemos aprovechar la definición que Brandi realiza del concepto de ruina (cualquier resto de una obra de arte que no pueda ser devuelto a su unidad potencial sin que la obra se convierta en una copia o en una falsificación de sí misma), para comprender la valoración negativa que otorga al concepto de copia, por no encontrarse en el nuevo objeto la autenticidad de la materia (inicial), época o autoría.

Por su parte, Muñoz Viñas señala que "todos los objetos son auténticos, auténticos por el hecho de existir ${ }^{19} . .$. " y tal como apunta $\mathrm{Eco}^{20}$ y Muñoz señala, "algo no es falso a causa de sus propiedades internas, sino en virtud de su pretensión de identidad".

Y tras analizar cada uno de estos conceptos, y volviendo a la necesidad de conservar el arte contemporáneo, podríamos apuntar que para algunos autores...la autenticidad de una obra reside en su originalidad y en su unicidad. Su historia atestigua y asegura su valor cultural y/o comercial a la vez que contribuye a forjar la autenticidad de su autor: el artista ${ }^{21}$.

Sin embarglo, los ready-made de Marcel Duchamp ya fueron presentados a principios del siglo XX. Estas obras están cargadas de un fuerte valor iconoclasta que pretende desvincularse del valor tradicional dado al objeto artístico. Marcel Duchamp desplazó el valor principal de la obra de arte a la idea, al exponer objetos manufacturados y descontextualizados, donde la mano del artista no podía vincularse con el valor de autenticidad.

Además en los años sesenta el artista hizo reproducir estas obras a diferentes artesanos (recordemos que una reproducción es una copia exacta de una obra bajo la supervisión del artista). Estas nuevas reproducciones fueron firmadas y numeradas para atestiguar su autenticidad. 
Eran auténticas porque Duchamp las concibió desvinculadas de la mano del artista y del concepto de originalidad y unicidad, por lo que el artista habría generado un nuevo tipo de objeto artístico en un intento de desvincularse del valor clásico que el mercado otorga a las obras de arte.

Por otro lado, centrándonos de nuevo en el ámbito de la restauración, no parece lógico que sea la intención de un restaurador, cuando vuelve a materializar una instalación o actualiza la tecnología obsoleta de una obra, la de llevar a engaño dolosamente con una intención fraudulenta. No tendría cabida en el mundo de la conservación el término de falsificación, pues no está en la intención del restaurador cometer fraude de ningún tipo.

Cuando la materia se convierte en parte anecdótica de la obra, el restaurador con, o bajo las directrices de los artistas, podría sustituirla o modificarla sin que por ello se resintiera la autenticidad del objeto simbólico.

Para Brandi la restauración supone el momento metodológico de reconocimiento de la obra de arte. Esto conlleva una confirmación del estatus ya establecido de la obra como objeto autónomo, es decir, su valor artístico no está en duda. Sin embargo, en el arte contemporáneo tenemos a menudo la necesidad de demostrar que nos encontramos ante una obra con valor/ $\mathrm{es}^{22}$. En este sentido, son numerosos los casos en los que el personal de mantenimiento de los museos ha dañado obras de arte contemporáneo expuestas, por no ser capaz de identificarlas como tales ${ }^{23}$.

El restaurador-conservador se encuentra a diario con la necesidad de cuidar y legar a las generaciones futuras las obras de arte que se producen en la actualidad: nuestras obras de hoy son el patrimonio de mañana. Nos vemos ante la necesidad moral de conservarlo y transmitirlo. La ética de la restauración sería observada en este caso, desde un prisma diferente al señalado por Wetering, pues el conservador, desde esta nueva perspectiva, se vería impelido a actuar sobre el objeto, al igual que un médico lo haría ante un paciente enfermo.

A su vez, las obras evolucionan, por lo que el restaurador se verá obligado a gestionar esa evolución, conservando para el futuro lo verdaderamente esencial de las mismas y desechando lo accesorio, y puesto que no podremos conservar todos los elementos integrantes de las obras, habrá que determinar qué es aquello esencial que las constituye, es decir, qué es lo que no puede verse afectado por el paso del tiempo sin que la intención artística se vea afectada, y todo ello, con el fin de atender a su preservación.

Por ello, sería auténtica una obra reinstalada en un museo, aunque su materia hubiera sufrido cambios o sustituciones para adaptarse al nuevo espacio expositivo, puesto que lo esencial no recaería sobre la materia en muchos casos, sino sobre la idea.

Será auténtica también la nueva edición de una obra, actualizada por motivos de obsolescencia tecnológica, donde sus elementos físicos hubieran podido ser sustituidos atendiendo al valor de funcionalidad; auténtica sería también la obra que en parte hubiera sido reconstruida por su autor.

En relación con este punto, cabe matizar la importancia que la figura del artista viene teniendo en los procesos de intervención. Conocida, respetada y valorada en todo momento, los procesos de intervención comienzan con el estudio de la intención artística y con el conocimiento de la opinión del artista en cuanto a la duración de sus obras, es decir, el restaurador intentará obtener del artista la respuesta a la pregunta fundamental ¿cómo afecta el paso del tiempo, inexorable, al conjunto de la obra?

Por nuestra parte, el respeto queda garantizado. Sin embargo, el artista, en tanto que creador, se siente capaz de restaurar sus propias obras y piensa a menudo que sería la persona idónea para hacerlo (no olvidemos que la ley de propiedad intelectual lo permite). Piensa generalmente que es la persona que mejor puede hacer las intervenciones pues, según él, sería capaz de hacerlas de un modo general e integrador, y no puntual (como haría un restaurador), disimulando perfectamente los problemas de conservación. Es éste un modo de ver la conservación que sólo puede tener un artista, y que denota el desconocimiento del código deontológico de la profesión. Según este código, un conservador nunca introduciría un nuevo momento de crea- 
ción artística en la obra y su intervención tendría como línea principal el respeto por la obra de arte, su entendimiento y el estudio de los distintos factores discrepantes que envuelven la toma de decisiones. Es decir, la conservación se constituye en un proceso intelectual complejo que acaba en la aplicación de unas técnicas específicas, fundamentadas en el estudio científico de la materia, los factores de deterioro y las patologías presentes en las obras. En el caso del arte contemporáneo, quizá sea mucho más complejo el manejo de las herramientas intelectuales necesarias para acabar proponiendo las actuaciones acertadas, que el manejo de las herramientas, técnicas y materiales habituales de los procesos de restauración.

Por otro lado, insistimos en la imposibilidad del artista de alejarse de su propia obra, como lo haría un restaurador. Hemos realizado numerosas entrevistas a artistas contemporáneos, desde el punto de vista de la conservación, en las que los propios entrevistados nos explicaban cómo habían realizado tratamientos de restauración de carácter general, con repintados de grandes zonas de las obras ante pequeños desperfectos, integración del color gracias a la aplicación de veladuras ${ }^{24} \ldots$ es decir, modificaciones de las obras que nos hacen pensar que quizá, en ocasiones, habría que proteger a las obras de sus propios creadores.

Es cierto que a menudo la obra, como en el caso de las instalaciones, es producida para cada exposición. No sería pues perenne, y sólo existiría materialmente mientras dure el evento.

Algunas obras pueden no dar lugar a una concreción, sino únicamente constituirse en un proyecto. Los Wall Drawings de Sol LeWitt, en ocasiones consisten en una serie de indicaciones e instrucciones que aporta el artista junto con un certificado de autenticidad y existencia de la misma.

Por lo general, el artista tiende a otorgar el valor de autenticidad a la idea de la obra, no a la materia de la misma, de manera que bajo su punto de vista, la conservación podría devenir inútil, e incluso ser rechazada dada la naturaleza transitoria de su materialización.

En conclusión, el término "autenticidad", ligado tradicionalmente a la materia de las obras, a la mano del artista, es decir, a lo único, ha sido redefinido no sólo para adaptarse al mundo del arte contemporáneo, sino también a la idea de valor cultural y social.

La realidad museográfica obliga a la realización de copias de exposición; a la realización de réplicas con la participación del artista ante la fragilidad de los originales o su dificultad de transporte; a la realización de reediciones, por parte de los propios artistas, de obras que se han perdido (presionados quizá en exceso por el mercado del arte). Parece obvio que el papel de la documentación devendrá fundamental en cada caso para determinar el status de cada nuevo objeto.

La actualización de estas obras, que de facto se produce, enfrenta al conservador con las cuestiones de autenticidad. En general, una autenticidad que busca la conformidad del artista con respecto a su intención en el momento de la nueva concreción. 


\section{NOTAS}

1 Un sistema relacional aplicado a la toma de decisiones muy útil es: The Decision-Making Model for the Conservation and Restoration of Modern and Contemporary Art, Foundation for the Conservation of Modern Art/Netherlands Institute for Cultural Heritage, Amsterdam 1999, on line, http://www. incca.org/files/pdf/resources/sbmk_icn_ decision-making_model.pdf.

2 H. Althöfer, Restauración de pintura contemporánea. Tendencias, materiales, ténica, Akal, Madrid 2003, pp. 17-18.

${ }^{3} \mathrm{H}$. Althöfer, "La restauración del arte moderno y contemporáneo", en, L. Righi, (coord), Conservare l'arte contemporanea, Nerea, Hondarribia 2006, pp. 71-78.

${ }^{4}$ Ibidem.

${ }^{5} \mathrm{M}$. Verbeeck Boutin, "Penser les pratiques après Cesare Brandi. Vers une praxéologie et une axiologie des restaurations en art contemporain" en Art d'Aujourd'hui patrimoine de demain. Conservation et restauration des oeuvres contemporaines, Institute National de Patrimoine, Saint Etienne 2009, pp. 57-64. Texto traducido por la autora.

${ }^{6}$ P. Montorsi, "Una teoría de la restauración del arte contemporáeno", en , L. Righi, (coord), Conservare l'arte contemporanea, Nerea, Hondarribia 2006, p. 42.

${ }^{7}$ Como apunta Paolo Martore en conferencia impartida en la Facultad de Bellas Artes de Valencia, en noviembre de 2012.

${ }^{8} \mathrm{M}$. Verbeeck Boutin, "De I'axiologie", en CeROArt [En ligne], 4 | 2009, puesto en línea el 29 de octubre 2009, consultado el 23 avril 2013. URL: http://ceroart.revues.org/1298.

${ }^{9}$ S. Muñoz Viñas, Teoría contemporánea de la restauración, Ed. Síntesis, Madrid 2003, p.151-152.

${ }^{10} \mathrm{~A}$. Riegl, El culto moderno a los monumentos, Visor, Madrid 1987.

${ }^{11} \mathrm{M}$. Verbeeck Boutin, "De I'axiologie", Op. Cit.

${ }^{12} \mathrm{C}$. Brandi, Teoría de la Restauración, Madrid, Ed. Alianza Forma, 2002.

13 G. Basile, Teoría e pratica del restauro in Cesare Brandi. Prima definizione dei termini, II Prato, Saonara 2007, p.80.

${ }^{14}$ M. Verbeeck Boutin, "De l'axiologie", Op. Cit.Traducción de la autora.

15 E. Wetering, "Conservationrestauration ethics and the problem of modern art", en Y. Hummelen y D. Sillé, Modern Art. Who Cares? Foundation for the Conservation of Modern Art/ Netherlands Institute for Cultural Heritage, Amsterdam 1999, pp. 247-249.

${ }^{16} \mathrm{D}$. Angoso [et al.] Las técnicas artísticas. El siglo XIX, Museo ThyssenBornemisza, Akal, Madrid 2005, p.69.

${ }^{17}$ C. Brandi, Op. Cit., p. 66.

${ }^{18}$ A. Macarrón y A. González, La conservación y la restauración en el siglo XX, Técnos/Alianza, Madrid 2007, p. 39.

${ }^{19}$ S. Muñoz Viñas, Op, Cit., p.93.

${ }^{20} \mathrm{U}$. Eco, Los límites de la interpretación, Lumen, Barcelona 2000.

${ }^{21}$ M.H. Breuil, "Autenticité des oeuvres contemporaines: production, conservation, reproduction", Les Cahiers du Musée des Confluences, vol. 8, 2011, p. 77-85.
22 Emilio Ruíz de Arcaute impartió en 2011 una interesante charla dentro de un ciclo de conferencias organizado por el Departamento de Conservación y Restauración de Bienes Culturales de la Universidad Politécnica de Valencia. La charla, titulada "Re-conocer el arte contemporáneo", tenía un título muy adecuado, el cual ponía de manifiesto la necesidad de reconocimiento social de la obra de arte contemporánea. Esta falta de reconocimiento y puesta en valor del objeto artístico es la causa de algunos accidentes que se han producido en los museos, debido muchas veces a descuidos del personal de limpieza. El público, en ocasiones, no es capaz de aprehender los valores que hacen del objeto un objeto artístico, por lo que éste no sería entendido como obra de arte.

${ }^{23}$ Una limpiadora de la Tate Britain de Londres tiró una bolsa de basura perteneciente a la obra Nueva creación de la primera presentación pública de un arte autodestructivo, de 1960. La bolsa fue recuperada en muy mal estado, por lo que el artista, Gustav Metzger, la sustituyó por otra inmediatamente.

${ }^{24}$ En la entrevista realizada a Miquel Barceló, en Mallorca en 2011, él mismo nos describió cómo repintó una de sus obras ante un pequeño desperfecto del soporte que había producido pérdida de capa pictórica. La opinión que Barceló tiene de los restauradores es absolutamente negativa; es contrario a la restauración de sus obras, al menos por parte de los profesionales de la restauración, y piensa que él es la persona idónea para realizar cualquier tratamiento. 